\title{
Ensinando Física Conceitual - Uma experiência em um Curso de Licenciatura em Física
}

\author{
Teaching Conceptual Physics - An Experience in a Physics Degree Course \\ José Guilherme Moreira*10 \\ ${ }^{1}$ Universidade Federal de Minas Gerais, Departamento de Física, Belo Horizonte, MG, Brasil
}

Recebido em 23 de setembro de 2019. Revisado em 27 de novembro de 2019. Aceito em 28 de fevereiro de 2020.

\begin{abstract}
Neste artigo, relato a experiência com duas disciplinas de Física Conceitual que são ofertadas para o curso de Física da UFMG, em especial para a Licenciatura, desde 2006. Apresento a motivação para essa oferta, descrevo a dinâmica utilizada que tem alta participação dos estudantes, relato o impacto que está tendo no curso e apresento alguns exemplos de questões discutidas nas disciplinas. Concluo defendendo a importância dessas disciplinas, principalmente, mas não exclusivamente, para a Licenciatura, com o objetivo de fazer uma revisão conceitual dos tópicos de Física do Ensino Médio.
\end{abstract}

Palavras-chave: Física Conceitual, Licenciatura em Física, Ensino Médio.

In this article, I report the experience with two Conceptual Physics disciplines that have been offered for the Physics course at UFMG, especially for the Degree, since 2006. I describe the motivation for this offer, describe the dynamics used with high student participation, I report the impact it is having on the course and I present some examples of questions discussed in the disciplines. I conclude by defending the importance of these disciplines, mainly, but not exclusively, for the Degree, in order to make a conceptual review of high school physics topics. Keywords: Conceptual Physics, Degree in Physics, High School.

\section{Introdução}

No início dos anos 2000, eu lecionava a disciplina Metodologia do Ensino de Física para o curso de Licenciatura na UFMG. Alguns alunos dessa disciplina, quase concluintes do curso, me fizeram o seguinte comentário: "Durante o curso nos ensinaram a resolver problemas de física do 'Halliday', mas temos dificuldades em responder a questões básicas do cotidiano". Eles se referiam ao livro Física, de Halliday e Resnick [1], que era adotado em algumas disciplinas básicas da área de exatas que são ofertadas na UFMG. Na conversa que se seguiu a esse comentário, eles me esclareceram um pouco mais sobre quais os tipos de questões eles tinham dificuldade e eu compreendi um pouco porque isso ocorria.

Nessa época, eu já conhecia o livro Física Conceitual, do Hewitt [2], que tinha sido traduzido para o português em 2002. Esse livro, editado na Califórnia e destinado para o ensino médio, apresenta o conteúdo de física sem formalismo, mas não é superficial.

Eu também tive contato com algumas experiências desenvolvidas nos EUA no final dos anos 1990 e início deste século que sinalizavam para um ensino de física com menos formalismo, com maior participação dos alunos, bem diferente das tradicionais aulas expositivas que tanto eu quanto os alunos estávamos acostumados.

*Endereço de correspondência: jmoreira@fisica.ufmg.br
Com isso, surgiu a ideia de ofertar dois tópicos - disciplina sem ementa pré-definida - destinados aos alunos de Licenciatura em Física que já estivessem na parte final do curso, ou seja, já tivessem cursado as disciplinas básicas. Esses tópicos têm como objetivo rever e aprofundar os principais conceitos básicos de física que podem ser abordados no Ensino Médio. A dinâmica proposta tem alta participação dos alunos e o livro texto é o do Hewitt [2], com a adição de alguns textos complementares.

Este artigo é um relato dessa experiência que está completando 14 anos. Inicialmente, apresentarei as condições que me levaram a propor esses tópicos, citando alguns trabalhos que me influenciaram na definição da dinâmica utilizada. Em seguida, detalharei essa dinâmica, após descreverei o impacto que essa proposta teve no curso de Licenciatura em Física e depois apresentarei alguns exemplos de questões que são discutidas nesses tópicos. No final, apresentarei algumas conclusões que podemos tirar desta experiência.

\section{Por que Ensinar Física Conceitual?}

O curso de Licenciatura em Física da UFMG tem a estrutura tradicional: os estudantes, que já tiveram contato com tópicos de física no Ensino Médio - mecânica, calor, ondas e ótica, eletromagnetismo -, quando entram no Ensino Superior revisitam esses tópicos com mais profundidade e com um formalismo matemático mais elaborado. 
Isso é feito em esquema semelhante ao antigo Ciclo Básico, originário da Reforma do Ensino de 1968, ou seja, as turmas das disciplinas básicas têm alunos de uma grande diversidade de cursos - as várias Engenharias, a Computação, a Geologia e as Ciências Exatas (Física, Química e Matemática, tanto Bacharelado, quanto Licenciatura). Com essa formação espera-se que o licenciando tenha um domínio formal dos principais conceitos físicos.

$\mathrm{Na}$ sequência do curso, os estudantes fazem uma série de disciplinas relacionadas com a prática de ensino e os estágios, além de se aprofundarem um pouco mais nos conteúdos de física, em especial na denominada física moderna. A maior parte das disciplinas de prática de ensino é ministrada no Departamento de Física e o restante no Departamento de Métodos e Técnicas de Ensino da Faculdade de Educação que também é responsável pelos estágios. Nessas disciplinas, é natural haver discussões conceituais sobre os conteúdos de física envolvidos, mas não é esse o enfoque principal.

Por outro lado, os Parâmetros Curriculares Nacionais de 1999 [3], já na primeira versão, sinalizavam para a importância de um ensino de física mais contextualizado no ensino médio.

"É preciso rediscutir qual Física ensinar para possibilitar uma melhor compreensão do mundo e uma formação para a cidadania mais adequada. ....

Não se trata, portanto, de elaborar novas listas de tópicos de conteúdo, mas sobretudo de dar ao ensino de Fúsica novas dimensões. Isso significa promover um conhecimento contextualizado e integrado à vida de cada jovem. ...

Para isso, é imprescindível considerar o mundo vivencial dos alunos, sua realidade próxima ou distante, os objetos e fenômenos com que efetivamente lidam, ou os problemas e indagações que movem sua curiosidade."

No entanto, a formação que era dada, tanto nas disciplinas básicas, quanto nas disciplinas mais avançadas, não tinha esse enfoque. Havia, e ainda há, uma grande preocupação com o formalismo, o que, sem dúvida, é essencial para a formação geral, mas é insuficiente quando se pensa na formação do futuro professor de Ensino Médio. Assim, a oferta de disciplinas que tivessem uma abordagem conceitual, com discussão de problemas contextualizados se fazia necessário.

Nessa mesma época, no primeiro número da revista Física na Escola, Gleiser [4] afirma: "Então, o ensino da física deve, necessariamente, conectar a visualização do fenômeno e sua expressão matemática'11 Eu discordo dessa frase porque acredito que as dificuldades dos estudantes de Ensino Médio na Matemática ofuscam a Física nos cursos tradicionais. Como a grande maioria desses estudantes não se encaminhará para a área de Exatas ou Engenharias, considero que não tem sentido o formalismo matemático excessivo - é usual se apresentar as equações da cinemática para quem ainda não sabe direito o que é uma função! Nessa linha, é muito interessante a mensagem "Ao professor" do livro do Hewitt [2]: “...

$1 \mathrm{O}$ destaque para necessariamente reproduz o original. a cinemática acaba se tornando uma espécie de 'buraco negro pedagógico' do ensino - muito tempo gasto para pouca física".

Além disso, a maioria dos livros-texto de Física básica tem uma grande preocupação com a resolução de problemas, alguns até apresentam receitas de como se fazer isso, mas pouca atenção é dada aos conceitos físicos envolvidos no fenômeno que está sendo analisado. Dessa forma, é usual o estudante saber resolver um problema conhece a fórmula e substitui os números corretamente -, sem conseguir explicar por que aquele fenômeno está ocorrendo. Assim, um dos objetivos das disciplinas de Física Conceitual é apresentar para os estudantes uma forma de raciocínio que não está presente na maioria desses livros-texto. Espero que, com o desenvolvimento desse raciocínio, o futuro professor consiga descrever e explicar um fenômeno sem ter que utilizar o jargão matemático.

\section{Como Apresentar a Abordagem em Física Conceitual?}

No início dos anos 2000, eu já tinha tido contato com algumas experiências em ensino de física desenvolvidas nos EUA - Arons [5], McDermot [6], Knight [7] - que sinalizavam para a importância de um ensino de física com maior participação dos alunos para que se atingisse uma aprendizagem significativa. Segundo McDermott [6], "aprendizagem significativa, quer dizer, da habilidade de interpretar e utilizar o conhecimento em situações diferentes daquelas em que ele foi inicialmente adquirido", e que isso "requer que os estudantes estejam intelectualmente ativos". Nesse trabalho, ela também chama a atenção para o fato de que "Questões que requeiram raciocínio qualitativo e explicação verbal são essenciais".

Eu também tive contato com os trabalhos de Mazur [8] que foi um dos primeiros a propor uma metodologia ativa de ensino, com alto grau de interação entre os estudantes na sala de aula. Um dos argumentos que ele utiliza que me marcou foi o de que "o aluno consegue explicar determinada questão ao colega melhor do que o professor, porque quanto mais se sabe sobre um assunto, mais difícil se torna explicá-lo, mais depressa se esquecem as dificuldades conceituais" [9].

Devido a esses trabalhos, decidi propor dois tópicos que utilizassem uma metodologia na qual os alunos têm que ficar mentalmente ativos e haja bastante interação entre eles. Além disso, esses tópicos têm um enfoque conceitual, discutindo questões contextualizadas no cotidiano dos estudantes e, quase sempre, exigindo respostas verbais.

\section{Uma Disciplina de Física Conceitual na Licenciatura}

Partindo dessas ideias e utilizando o livro do Hewitt [2], elaborei uma proposta de tópicos a serem ministrados, principalmente, para os alunos de Licenciatura em Física após eles terem a formação formal em física, ou seja, nos períodos finais de seu curso. O objetivo é rever e 
aprofundar os principais conceitos básicos de Física que podem ser abordados no Ensino Médio. São também apresentados alguns tópicos que podem estar além desse nível, os quais eu considero que o professor de Física tem que saber para poder responder a questões do dia-a-dia.

Essa proposta consta de duas disciplinas de $60 \mathrm{~h}-\mathrm{a}$ Física Conceitual I cobre os tópicos de mecânica, propriedades da matéria e física térmica; a Física Conceitual II, os tópicos de vibrações e ondas, eletromagnetismo, luz, física atômica e nuclear e teoria da relatividade. Esses tópicos são abordados no nível do livro, ou seja, ensino médio, sem utilização de formalismo matemático, mas algumas questões um pouco mais elaboradas também são apresentadas. A maioria das questões tem um enfoque mais qualitativo - se relata uma situação e se pede para o estudante explicar por que isso acontece dessa forma ou semiquantitativo - a mudança de um parâmetro fará com uma grandeza fique maior, menor ou permaneça com o mesmo valor. Poucas questões têm abordagem quantitativa e são principalmente do tipo "Estime ...". À frente, apresentarei alguns exemplos dessas questões.

A dinâmica do curso consta da divisão da turma em grupos de quatro ou cinco alunos que, em cada aula, devem responder a um questionário com perto de dez perguntas. As respostas devem ser dadas no nível do livro, ou seja, um estudante do ensino médio deve ter capacidade de entendê-las. Elas não devem ser extensas, mas não podem ser sucintas, ou seja, não podem pular etapas do raciocínio. Respostas que se limitem a apresentar uma fórmula são altamente desincentivadas, assim como aquelas que utilizem formalismo matemático desnecessário. O tópico de cada aula é avisado no início do curso e é basicamente um dos capítulos do livro que o aluno deve ler antes da aula. As respostas de cada grupo às perguntas desse questionário são corrigidas e entregues ao grupo na aula seguinte - esse feedback rápido é muito importante. A cada quatro ou cinco questionários, acontece uma aula em que são apresentadas as principais dúvidas que apareceram em cada capítulo.

Com essa dinâmica, se consegue o que foi descrito na seção anterior: alta participação dos alunos que têm que ficar mentalmente ativos e um ambiente de ensino colaborativo, com bastante interação entre eles.

Essa dinâmica de discussão nos grupos foi detalhadamente analisada na Tese de Doutorado em Educação de Mendonça [10]. Para essa tese, ele gravou as aulas de uma turma de Conceitual II durante um semestre e com esse material tentou "compreender como se estrutura e se desenvolve a atividade em grupo de resolução de questões conceituais". Uma das conclusões dessa Tese é que "Identificamos uma contradição entre a física que é ensinada no curso de física na instituição investigada e a necessidade de se aprender física para além de solução de problemas clássicos, tal como tradicionalmente apresentado nessas disciplinas, cujo excessivo formalismo matemático acaba por se revelar inoperante e sem significado para os estudantes."

\section{Impacto}

Essas duas disciplinas estão sendo ofertadas desde 2006/1. Até 2013, a Física Conceitual I era ofertada no primeiro semestre e a Física Conceitual II no segundo, sempre no noturno. Em alguns semestres se ofertou também no diurno com aula das 17:00 às 18:40. A partir de 2014, as duas disciplinas estão sendo ofertadas todo semestre no primeiro semestre, a Física Conceitual I no noturno e a Física Conceitual II no diurno (no horário das 17:00); no segundo semestre, se inverte.

Nesses 27 semestres, foram ofertadas 22 turmas de Física Conceitual I e 20 de Física Conceitual II. Um total de 501 estudantes se matricularam na primeira - 425 aprovados, 38 reprovados e os outros 38 foram infrequentes ou trancaram a disciplina - e 371 estudantes na segunda - 316 aprovados, 15 reprovados e os outros 40 infrequentes ou trancaram. A maioria desses estudantes é da Licenciatura, mas mais recentemente, tem havido uma demanda de alunos do Bacharelado, em especial nas turmas do diurno 2

Neste semestre (2019/2), a turma de Física Conceitual I, no horário de 17:00, está com 44 alunos - 25 da Licenciatura e 19 do Bacharelado -, e a Física Conceitual II, no noturno, com 15 alunos, somente um do Bacharelado. Nas aulas em que os grupos têm que fazer os questionários, o índice de participação é enorme - só um ou dois ausentes e os alunos permanecem ativos por aproximadamente 90 minutos; nas aulas de dúvidas, em que o professor faz uma exposição discutindo as questões em que eles tiveram mais dificuldades, o índice de presença fica acima de $60 \%$ (vale ressaltar que, no dia seguinte, o professor envia aos alunos um arquivo pdf com essa aula).

Desde o início da oferta dessas disciplinas, elas são ofertadas como um tópico, sempre pelo mesmo professor, o autor deste artigo. Esse tópico entra no histórico escolar do aluno como uma atividade optativa com conteúdo de Física. Ao longo do curso, os alunos, tanto da Licenciatura quanto do Bacharelado, devem fazer um mínimo de $240 \mathrm{~h}$ dessas atividades e cada tópico é de 60 h. Devido à grande aceitação desses dois tópicos pelos estudantes e o impacto em sua formação, em especial dos licenciandos, na nova estrutura curricular implantada em 2019 o Colegiado do curso decidiu que esses tópicos passem a ser duas disciplinas obrigatórias para a Licenciatura ${ }^{3}$ com as seguintes ementas [11]:

Física Conceitual A - Aprofundamento nos conceitos básicos de Física com enfoque de Ensino Médio e contextualização no cotidiano, com aplicações em problemas relacionados ao meio ambiente, nas áreas de: mecânica da partícula e do corpo rígido; propriedades da matéria - sólidos e fluidos; física térmica.

\footnotetext{
2 Na UFMG, o curso de Física no diurno é ofertado nas modalidades Bacharelado e Licenciatura e, no noturno, somente Licenciatura.

3 Para o Bacharelado, essas disciplinas serão optativas, mas consideradas de conteúdo geral, não entram no grupo de disciplinas com conteúdo de Física.
} 
Física Conceitual B - Aprofundamento nos conceitos básicos de Física com enfoque de Ensino Médio e contextualização no cotidiano, com aplicações em problemas relacionados ao meio ambiente, nas áreas de: oscilações e ondas; eletromagnetismo; ótica; física quântica; estrutura atômica e nuclear; teoria da relatividade.

Os pré-requisitos da Física Conceitual A são duas disciplinas básicas 4 Fundamentos de Mecânica e Fundamentos de Mecânica dos Fluidos e Termodinâmica. Para Física Conceitual B, os pré-requisitos são Fundamentos de Oscilações, Ondas e Óptica e Fundamentos da Teoria da Relatividade - isso subentende que o aluno já cursou Fundamentos de Eletromagnetismo e deve estar cursando Introdução à Física Quântica.

\section{Alguns Exemplos de Questões}

Nesta seção vou apresentar alguns exemplos de questões - uma qualitativa, duas semiquantitativas e uma quantitativa. Essas questões foram escolhidas para também mostrar alguns conceitos que habitualmente os estudantes têm dificuldades que, quase sempre estão relacionadas com tópicos pouco abordados no ensino médio. Esse fato pode ser explicado pelo fato de que vários alunos já exercem a docência ou são monitores em escolas de Ensino Médio ou em cursinhos, então têm maior domínio dos conteúdos usuais dessa etapa de ensino.

O exemplo de questão qualitativa aborda a hidrodinâmica, tópico no qual a maioria dos estudantes aplica a equação da continuidade e/ou a de Bernoulli de forma equivocada. O exercício 55, p.267 do livro Física Conceitual do Hewitt, $12^{\mathrm{a}}$ edição [2], é um exemplo:

Os desembarcadouros são construídos sobre estacas que permitem a livre passagem da água, como representado na Figura 1. Por que um desembarcadouro construído com paredes sólidas seria desvantajoso para os navios que tentam atracar lateralmente?

A maioria dos grupos responde corretamente que nos desembarcadouros sobre estacas a velocidade da água é similar dos dois lados do barco, enquanto em um desembarcadouro com paredes sólidas essa velocidade é maior

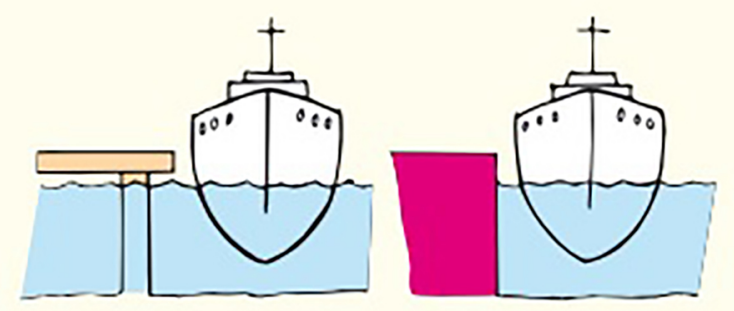

Figura 1: Representação dos embarcadouros. Retirado de Hewitt [2].

\footnotetext{
4 A Estrutura Curricular do curso de Física da UFMG - Licenciatura e Bacharelado - e as ementas das disciplinas podem ser consultadas em //www.fisica.ufmg.br/graduacao/ (acesso em $13 /$ set/2019).
}

de um lado do que o outro - essa diferença na velocidade provoca uma diferença de pressão entre os dois lados do barco.

O problema é que grande parte das respostas indica uma velocidade da água maior entre o barco e a parede, fazendo com que surja uma força empurrando o barco para o cais. O argumento é que, como a área de fluxo é menor entre o barco e o cais, a velocidade seria maior nesse lado. Isso não está correto porque a equação da continuidade só é aplicável para um fluxo em sequência, não pode ser utilizada em bifurcações. Na verdade, devido à viscosidade, a velocidade da água entre o barco e o cais é bem menor do a do outro lado e o barco é empurrado para fora. Considero que essa dificuldade esteja relacionada com uma deficiência na grade curricular do curso de Física em vigor até 2018 que não aborda a hidrodinâmica em nenhuma disciplina obrigatória.

Como exemplos de questões semiquantitativas apresentarei duas questões relacionadas com a dinâmica da rotação, uma abordando o conceito de inércia rotacional e a outra o conceito de momentum angular. O primeiro exemplo é a questão 3, p.146 do livro Física Conceitual do Hewitt, $12^{\mathrm{a}}$ edição [2]:

Iniciando do repouso, o disco maciço $\mathrm{A}$, a bola maciça $\mathrm{B}$ e o aro $\mathrm{C}$ disputam uma corrida rampa abaixo, como representado na Figura 2. Ordene-os segundo a ordem de chegada na base da rampa: vencedor, segundo e terceiro lugar.

Essa é uma questão tradicional para se discutir os conceitos de inércia rotacional e conservação da energia: chega primeiro quem tem menor inércia rotacional (B - a esfera maciça) e por último quem tem a maior ( $\mathrm{C}$ - o aro). No entanto, é normal se ter a resposta de que os três chegam juntos no final da rampa ou a resposta invertida (o aro é o mais rápido) ou ainda que dependerá da massa e do raio dos objetos.

Outro exemplo de questão semiquantitativa aborda o conceito de momento angular - eles têm grande dificuldade em utilizar o caráter vetorial dessa grandeza para explicar movimentos como o da bicicleta ou o do pião. Este é o exercício 8, p. 152 do livro Física Conceitual do Hewitt, 9 a edição:

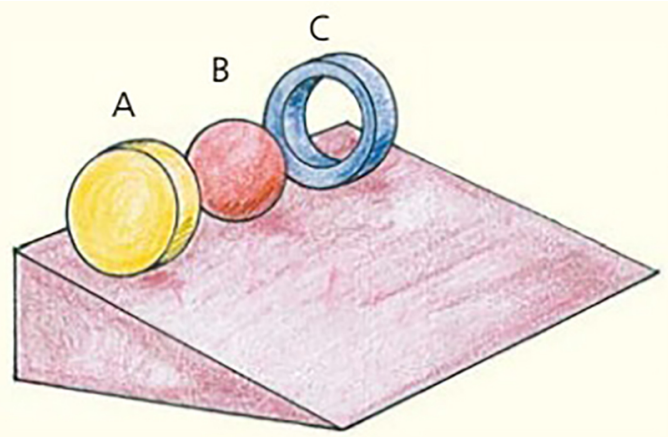

Figura 2: A rampa com o disco, a bola e o aro. Retirado de Hewitt [2] 
Um jogador de basquete deseja equilibrar uma bola sobre a ponta de um de seus dedos. Ele será mais bem sucedido com uma bola que está girando ou com uma que está estacionária? Que princípio físico justifica sua resposta?

Nessa questão é fundamental o conceito vetorial de torque provocando variação do momento angular: se a bola não está girando (momento angular nulo) e há um pequeno desequilíbrio (o centro de massa da bola sai da vertical), surge um torque que faz a bola rolar e sair de cima do dedo, caindo no chão. Com a bola girando, ela possui momento angular e, quando há o desequilíbrio e o centro de massa se desloca, surge um torque que provoca variação desse momento angular e a bola precessa. Isso dá tempo para o atleta deslocar seu dedo e reequilibrar a bola.

É interessante notar que esse exercício não consta das edições mais novas do livro do Hewitt - sem dúvida esse é um tópico que não costuma ser abordado no Ensino Médio por envolver fortemente o caráter vetorial do torque e do momento angular. No entanto, esse tipo de questão é apresentado na Física Conceitual I porque considero que um professor de Física deve saber explicar como funciona um giroscópio.

Como exemplo de questão quantitativa, uma questão que não faz parte do livro do Hewitt [2], mas que é apresentada no tópico porque envolve a habilidade de estimar valores de grandezas físicas que considero fundamental para um professor de Física:

Estime as seguintes velocidades em $\mathrm{m} / \mathrm{s}$ (explicite seu raciocínio):

1. o crescimento de seu cabelo.

2. uma gota de chuva.

No item A, é comum o grupo apresentar uma resposta em que supuseram um valor em torno de $2 \mathrm{~cm}$ por mês e apresentam uma resposta de $7,72 \times 10^{-9} \mathrm{~m} / \mathrm{s}$ ! Isso significa que uma medida que tinha um único algarismo, depois de algumas contas, passou a ter três algarismos. Esse erro é muito frequente e razoavelmente persistente - grupos que já tiveram esse erro e foi-lhes chamada a atenção para o absurdo que estavam cometendo, reincidem em situações semelhantes.

No item B, a maioria dos grupos tem grande dificuldade em fazer estimativas desse tipo. Considero que isso é um reflexo das disciplinas tradicionais não se preocuparem com essa habilidade, os livros-texto preferem apresentar os problemas com todos os valores das grandezas já atribuídos.

\section{Conclusões}

Neste trabalho, apresentei a proposta de duas disciplinas de Física Conceitual ofertadas para o curso de Licenciatura em Física da UFMG desde 2006. Essas disciplinas são ofertadas como tópicos, optativos tanto para a Licenciatura, como para o Bacharelado, mas com a implantação da versão curricular de 2019 passarão a ser disciplinas obrigatórias para a Licenciatura e optativas para o Bacharelado.

A ideia central dessas disciplinas é rever e aprofundar os principais conceitos básicos de Física que podem ser apresentados no Ensino Médio com uma abordagem em que uma linha de raciocínio conceitual, não formal, seja primordial. Nos quase 14 anos em que essas disciplinas têm sido ofertadas tem havido uma excelente receptividade por parte dos estudantes, não só da Licenciatura, mas também do Bacharelado.

Além disso, defendo a importância dessa revisão dos conceitos ser realizada no final do curso de Física, em especial para a Licenciatura. O enfoque das disciplinas que estou propondo não é apresentar um dado conteúdo, isso o estudante deve ter visto anteriormente. O objetivo é como utilizar esse conhecimento para analisar situações físicas sem utilização de formalismo matemático. Assim, por exemplo, o conceito de momento de inércia é utilizado, mas é considerado pré-requisito para estas disciplinas.

Acredito que um professor ao dar suas aulas serve como exemplo para os futuros professores, especialmente em um curso de Licenciatura. Assim, o exemplo que eu tenho tentado dar com estas duas disciplinas é da importância de um ensino de Física para o Ensino Médio mais conceitual, menos formal.

\section{Agradecimentos}

Agradeço a Douglas H. Mendonça pela leitura cuidadosa do artigo e pelas várias sugestões que ele me encaminhou.

\section{Referências}

[1] D. Halliday e R. Resnick, Física (Livros Técnicos e Científicos, Rio de Janeiro, 1996).

[2] P.G. Hewitt, Física Conceitual (Bookman, Porto Alegre, 2015), $12^{\mathrm{a}} \mathrm{ed}$.

[3] BRASIL, Parâmetros Curriculares Nacionais: Ensino Médio (Ministério da Educação, Brasília, 1999).

[4] M. Gleiser, Física na Escola 14 (2000).

[5] A.B. Arons, Teaching Introductory Physics (John Wiley, New York, 1997).

[6] L.C. McDermott, Am. J. Phys. 61, 295 (1993)

[7] R.D. Knight, Five Easy Lessons (Addison Wesley, San Francisco, 2004).

[8] E. Mazur Peer Instruction (Prentice Hall, New Jersey, 1997).

[9] E. Mazur, Gazeta de Física 26, 18 (2003)

[10] D.H. Mendonça, A Resolução de Problemas Conceituais em Física: uma análise a partir da Teoria da Atividade Tese de Doutorado, Faculdade de Educação, Universidade Federal de Minas Gerais Belo Horizonte, 2019

[11] Projeto Pedagógico Curso de Física: Versão Curricular 2019-1 Disponível em: https://www.fisica ufmg.br/graduacao/wp-content/uploads/sites/3/ 2019/07/projeto_pedagogico2019.pdf, acessado em $19 / 11 / 2019$ 